\title{
An empirical study of factors influencing lime slaking Part II: Lime constituents and water composition
}

\author{
JH Potgieter ${ }^{1 *}$, SS Potgieter ${ }^{2}$ and D de Waal ${ }^{3}$ \\ ${ }^{1}$ Department of Chemical \& Metallurgical Engineering, Technikon Pretoria, Private Bag X 680, Pretoria, 0001, South Africa \\ ${ }^{2}$ Department of Chemistry and Physics, Technikon Pretoria, Private Bag X 680, Pretoria, 0001, South Africa \\ ${ }^{3}$ Department of Chemistry, University of Pretoria, Pretoria, 0001, South Africa
}

\begin{abstract}
Chloride, carbonate and sulphate ions are common constituents of many waters and are often found in high concentrations in water used for the slaking of lime. Furthermore, magnesium oxide is a common constituent of many limestones and can, after calcining, also affect the hydration rate of the lime if it is present as magnesium oxide. The purpose of this investigation was to assess quantitatively the effect of these various chemical influences, whether it be from a geological origin or present in the slaking water, on the slaking rate of lime. It was found that the presence of chloride ions in the slaking water increased the lime reactivity, while sulphate and carbonate ions in the slaking water retarded the hydration reaction. Magnesium oxide also had a detrimental effect on the slaking rate of lime.
\end{abstract}

Keywords: Lime, slaking, chloride, sulphate, carbonate.

\section{Introduction}

Limestone (mainly $\mathrm{CaCO}_{3}$ ) is one of the most widely occurring industrial minerals world-wide. It is therefore not surprising that lime, obtained by calcining limestone, is a frequently used industrial base and features on the list of the top 50 industrial chemicals (National Lime Association, 1990). When applied as an alkali, unslaked lime, $\mathrm{CaO}$, is commonly converted to slaked lime, $\mathrm{Ca}(\mathrm{OH})_{2}$, by reacting it with water. The conversion of limestone to lime and its slaking with water, can be represented by the following reactions:

$$
\begin{array}{ll}
\mathrm{CaCO}_{3}(\mathrm{~s}) & \rightarrow \mathrm{CaO}(\mathrm{s})+\mathrm{CO}_{2}(\mathrm{~g}) \\
\mathrm{CaO}(\mathrm{s})+\mathrm{H}_{2} \mathrm{O}(\mathrm{l}) \rightarrow \mathrm{Ca}(\mathrm{OH})_{2}(\mathrm{aq})
\end{array}
$$

Although it is the $\mathrm{Ca}(\mathrm{OH})_{2}$ species that is desired in the application, its production is closely linked to a number of physical and chemical influences. These include, among others, the origin of the limestone from which it is derived, calcining conditions in the kiln and constituents in the water used for slaking. The effects of calcining and storage conditions have already been reported on in a separate paper (Potgieter et al., 2002a) but the effects of different chemical constituents in both the limestone material as well as the water used for slaking have not been discussed.

Chloride, carbonate and sulphate ions are common constituents of many waters and are often found in high concentrations in water used for the slaking of lime. Furthermore, $\mathrm{MgO}$ is a common constituent of many limestones and can, after calcining, also affect the hydration rate of the lime if it is present as $\mathrm{MgO}$. The purpose of this investigation was to assess quantitatively the effect of these various chemical influences, whether it be from a geological origin or present in the slaking water, on the slaking rate of lime.

* To whom all correspondence should be addressed.

III+27 123186281 ; fax: +27 123186275 ; e-mail: hermanp@techpta.ac.za Received 30 January 2002; accepted in revised form 21January 2003
Ultimately the aim is to assist consumers in the correct choice and optimal use of the product.

\section{Experimental procedure}

Samples: The samples investigated were obtained from Lime Acres in the Northern Cape Province and represent the chemically most pure limestone deposit in South Africa. It is also the source of the bulk of unslaked lime sold in the country. The chemical composition of the material, as obtained by XRF analysis, is given in Table 1. Using the values for the percentage $\mathrm{CaO}$ in the sample, it was calculated that the maximum amount of $\mathrm{CaCO}_{3}$ in the Lime Acres material is $98.7 \%$.

Slaking test: The experimental procedure used has been described in detail (Potgieter et al., 2002b). It basically entails monitoring the time that a fixed mass of lime of parti-

\begin{tabular}{|c|c|}
\hline \multicolumn{2}{|c|}{$\begin{array}{c}\text { TABLE } 1 \\
\text { Chemical composition of } \\
\text { the lime used in this } \\
\text { investigation }\end{array}$} \\
\hline Element & $\%(m / m)$ \\
\hline $\begin{array}{c}\mathrm{SiO}_{2} \\
\mathrm{Al}_{2} \mathrm{O}_{3} \\
\mathrm{Fe}_{2} \mathrm{O}_{3} \\
\mathrm{Mn}_{2} \mathrm{O}_{3} \\
\mathrm{TiO}_{2} \\
\mathrm{CaO} \\
\mathrm{MgO} \\
\mathrm{P}_{2} \mathrm{O}_{5} \\
\mathrm{SO}_{3} \\
\mathrm{Cl} \\
\mathrm{K}_{2} \mathrm{O} \\
\mathrm{Na}_{2} \mathrm{O} \\
\mathrm{LOI} \\
\mathrm{Total} \\
\mathrm{Av} . \mathrm{CaO} \\
\mathrm{CO}_{2}\end{array}$ & $\begin{array}{c}0.8 \\
0.3 \\
0.3 \\
1.1 \\
<0.1 \\
94.1 \\
2.1 \\
0.0 \\
<0.1 \\
0.0 \\
<0.1 \\
0.2 \\
1.1 \\
100.0 \\
87.8 \pm 0.2 \\
0.7\end{array}$ \\
\hline
\end{tabular}
cle size 1 to $2 \mathrm{~mm}$ takes to raise the temperature of a selected mass of water from $20^{\circ} \mathrm{C}$ to $60^{\circ} \mathrm{C}$.

Grit measurement: An additional test introduced in this investigation in order to distinguish between hydration rates in various solutions, is a determination of the amount of grit produced during 


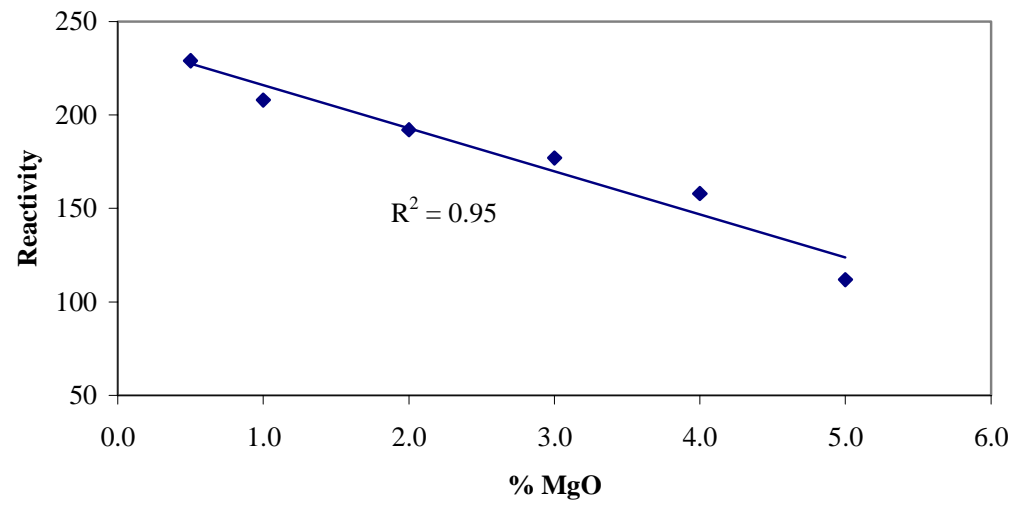

Figure 1

Effect of various concentrations of $\mathrm{MgO}$ on the reactivity of lime

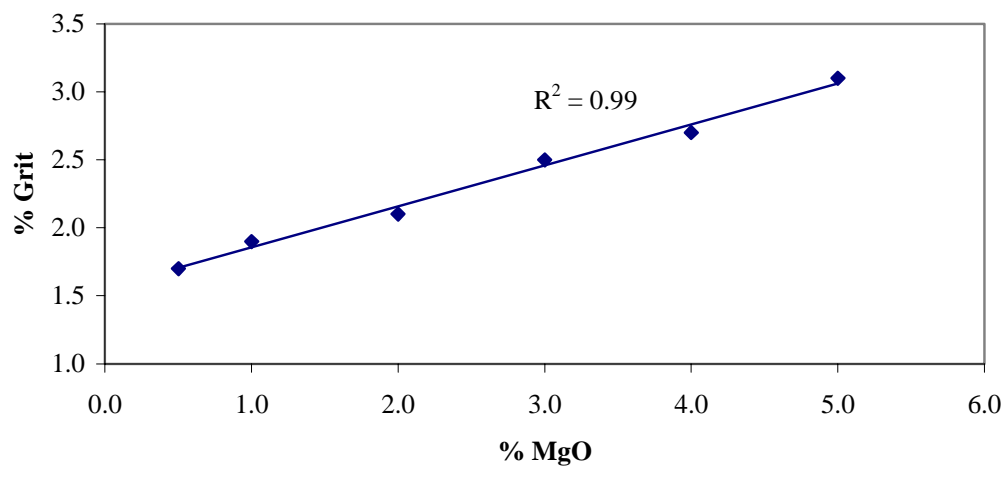

Figure 2

Effect of various concentrations of $\mathrm{MgO}$ on the \% grit

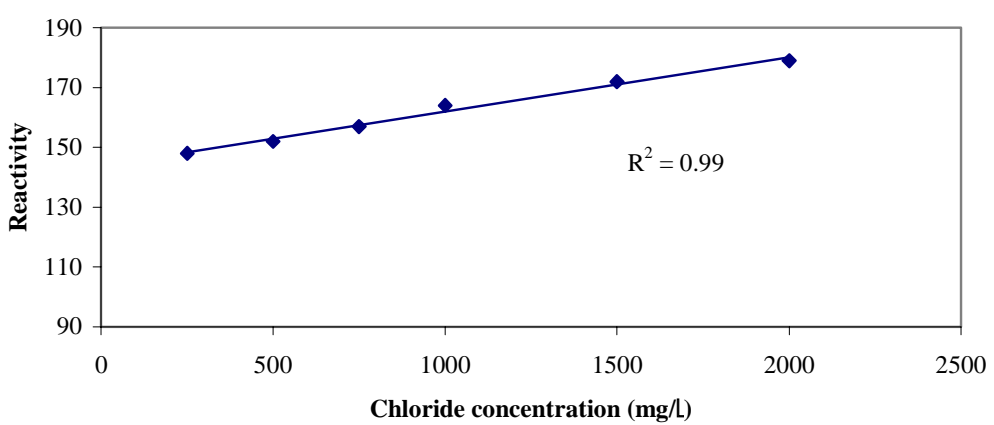

Figure 3

Effect of various chloride concentrations on the reactivity of lime

\section{Results and discussion}

Due to the similarity in chemical behaviour of calcium and magnesium, geologically formed limestones often contain significant amounts of magnesium impurities, mostly as $\mathrm{MgCO}_{3}$. If the magnesium content becomes large enough, such material is referred to as dolomitic limestone and in extreme cases even dolomite. It is therefore important to assess the effect of this chemical impurity on its hydration behaviour. In order to do so, various amounts of $\mathrm{MgO}$ were added to the calcined limestone to determine the effect on the hydration behaviour. However, it should be kept in mind that this does not reflect the real situation that occurs in practice; $\mathrm{MgCO}_{3}$ decomposes at a lower temperature than $\mathrm{CaCO}_{3}(\mathrm{CRC}, 1996)$ to the corresponding oxide and will, under practical operating conditions in a lime kiln, tend to become hard burnt if present in the limestone. It should therefore theoretically lower the reactivity or slaking rate of the lime.

The effect of $\mathrm{MgO}$ contamination in a naturally occurring calcined South African limestone, was simulated by mixing various amounts of $\mathrm{MgO}$ with unslaked lime. The effect on the reactivity of the lime is graphically displayed in Fig. 1. It seems that small additions of $\mathrm{MgO}$ initially increase the slaking rate of the lime undergoing hydration (compare with values shown in Fig. 3), before causing a major drop in the slaking rate. Although it is well known (Addis, 1994) that $\mathrm{MgO}$ hydrates much slower than $\mathrm{CaO}$, the apparent initial increase can be explained by the fact that the added $\mathrm{MgO}$ was chemically pure and not hard burnt as it would have been under practical operating conditions. Apart from decreasing the hydration rate of the lime, a most interesting observation about the effect of $\mathrm{MgO}$ on the amount of grit produced in the slaking reaction is displayed in Fig. 2. There seems to be a sharp increase in the amount of grit produced in the slaking reaction by the presence of even a small amount of $\mathrm{MgO}$. This has severe consequences in the operation of commercial slakers, where the build-up of grit can lead to increased maintenance cost and down-time for cleaning purposes.

Very often process water or effluent is used for the slaking of lime. Such waters normally contain high concentrations of impurities, most notably chlorides, sulphates and carbonates. Impurities in water are known to affect the rate of hydration of unslaked lime. However, (Oates, 1998) observed that relatively little has been reported on their effect on the production of lime slurries. Recently Gheevarhese et al.(2002) reported

the slaking procedure. For this purpose, the lime-water reaction mixture was transferred to a $0.5 \mathrm{~mm}$ pore size sieve for screening after the reactivity test. The rational behind this was that any slaked lime would form very fine $\mathrm{Ca}(\mathrm{OH})_{2}$ particles that would easily pass through this sieve size, while the coarser, unhydrated parts and impurities would be trapped by this sieve size. The residue trapped on the sieve was dried in an oven for $3 \mathrm{~h}$ at $100^{\circ} \mathrm{C}$ and then cooled. After cooling, the residue was gently brushed with a paint brush until all the fine powder was removed and only the coarser and hard solid particles were left on the sieve. This final residue was weighed to calculate the $\%$ grit as a percentage of the original mass of lime used in the test. that sulphates in slaking water significantly retard the hydration reaction of several South African limes from various geological origins.

Although the effect of impurities on the total solubility of $\mathrm{Ca}(\mathrm{OH})_{2}$ can be calculated from first principles, such calculations cannot quantify the effect on the slaking kinetics. Again, solubility principles allow one to predict that chlorides, which as $\mathrm{CaCl}_{2}$ are more soluble than $\mathrm{Ca}(\mathrm{OH})_{2}$, should facilitate the dissolution of lime and consequently accelerate the slaking reaction. At the same time carbonates and sulphates, which form more insoluble calcium compounds than $\mathrm{CaO}$, should retard the slaking process. However, in none of these cases can these influences be quantitatively predicted. 
Figure 3 shows that there is a direct relationship between the reactivity or slaking rate of lime and the concentration of the chloride in the water. In Fig. 4 it is found that the amount of grit also increases with the increase in chloride concentration. It seems that the chloride, in enhancing the solubility of the lime, allows the grit that was originally trapped in the lime particles to be freed and this increases the amount collected on the sieve in the grit test.

The effect of carbonate and sulphate ions in the slaking water on the hydration rate of the lime, is shown in Fig. 5. It is clear that there is again a linear relationship between the hydration rate and the carbonate concentration. However, under these conditions the rate of slaking decreases linearly with an increasing concentration of carbonate ions in the slaking water.

As Fig. 6 indicates, the amount of grit produced by the carbonate during the slaking process of the lime stays relatively constant. This can probably be ascribed to the fact that the $\mathrm{CaCO}_{3}$ particles that form during the hydration process are very fine and pass the sieve size used in the grit test easily. The major contributor to the grit in this case is the insoluble impurities normally present in the lime and which are released in the slaking step.

It can also clearly be seen that the slaking rate decreases rapidly with increasing sulphate concentration, although not in a linear fashion. This corresponds to previous observations (Gheevarhese et al., 2002) when using a different measuring technique. The decrease in hydration rate in both the cases where carbonate ions and sulphate ions are present in the slaking water can be explained by assuming that insoluble layers of either $\mathrm{CaCO}_{3}$ or $\mathrm{CaSO}_{4}$ partially or completely coat the lime particles and prevent them from further dissolution or slow down the dissolution process. However, it can be concluded from the data presented in Fig. 5 that the retarding action of carbonates on the hydration rate is more severe than that of the same concentration of sulphate ions. This observation can be explained by keeping in mind that $\mathrm{CaCO}_{3}$ is less soluble than $\mathrm{CaSO}_{4}$.

The data presented in Fig. 6 show that the amount of grit encountered increased when sulphate ions were present in the slaking water. It seems from visual observations that the $\mathrm{CaSO}_{4}$ precipitate formed when sulphate ions are present, is coarser than the $\mathrm{CaCO}_{3}$ formed in the slaking process when carbonate ions are present. It can thus be concluded that the increase in the amount of grit in the case when sulphate ions are present is not just due to soluble impurities alone, but also some coarse $\mathrm{CaSO}_{4}$ precipitate. This latter contribution therefore caused an ever-increasing amount of grit compared to the previous instance when carbonate ions were present in the slaking water and

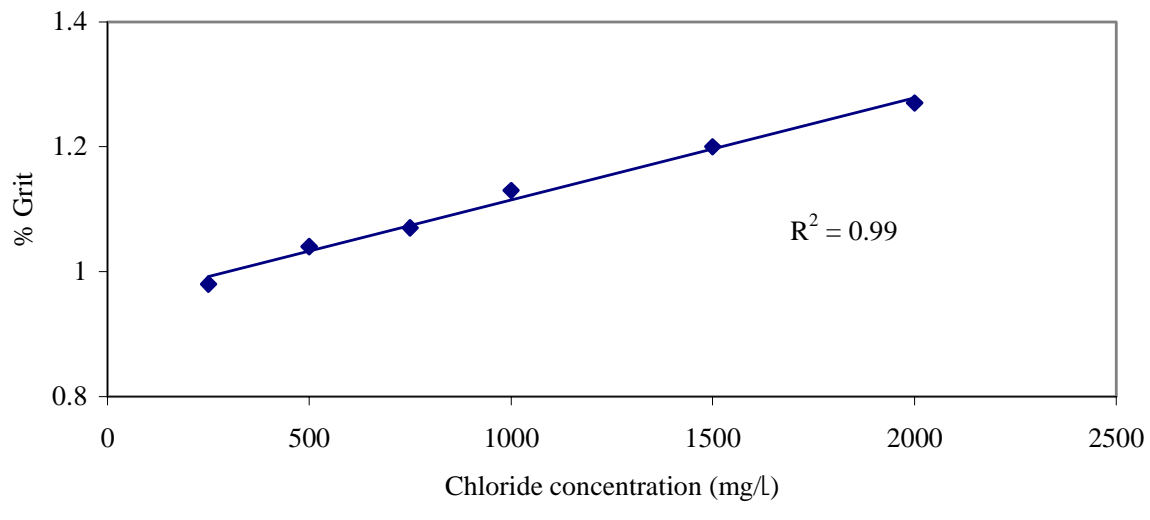

Figure 4

Effect of various chloride concentrations on the \% grit

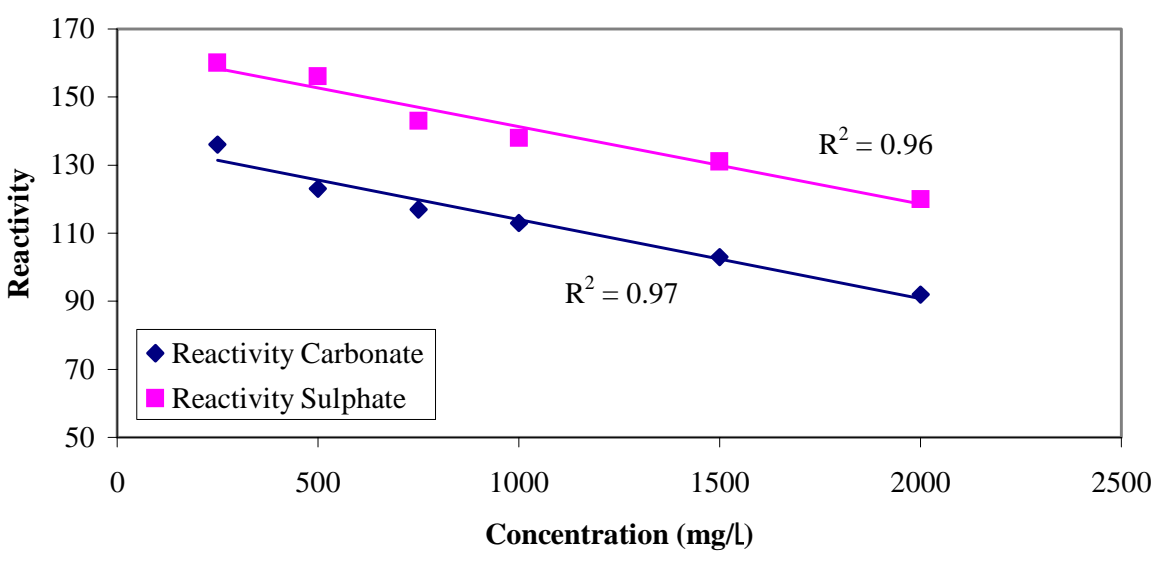

Figure 5

The effect of various sulphate and carbonate concentrations on the reactivity of lime 


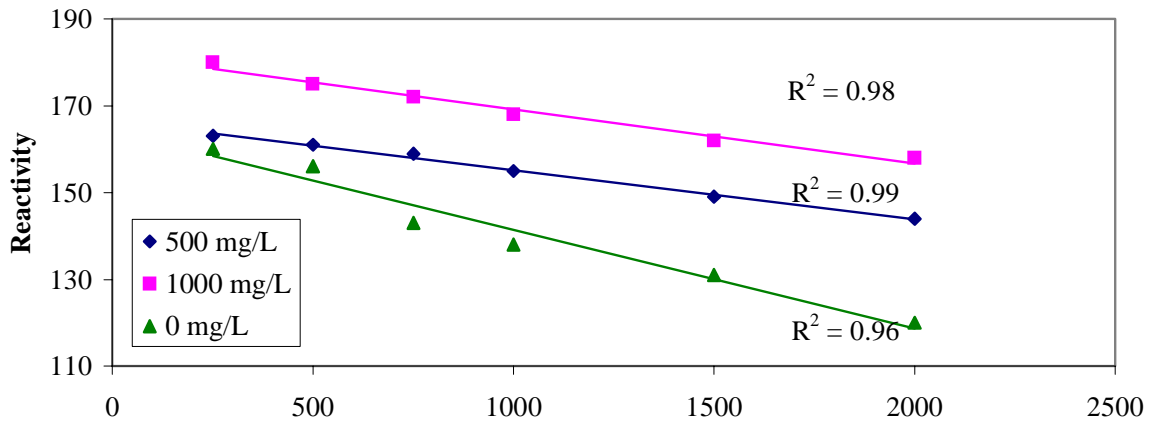

Sulphate concentration (mg/l)

Figure 7

The effect of various chloride concentrations on lime slaking in sulphate ion-containing solutions

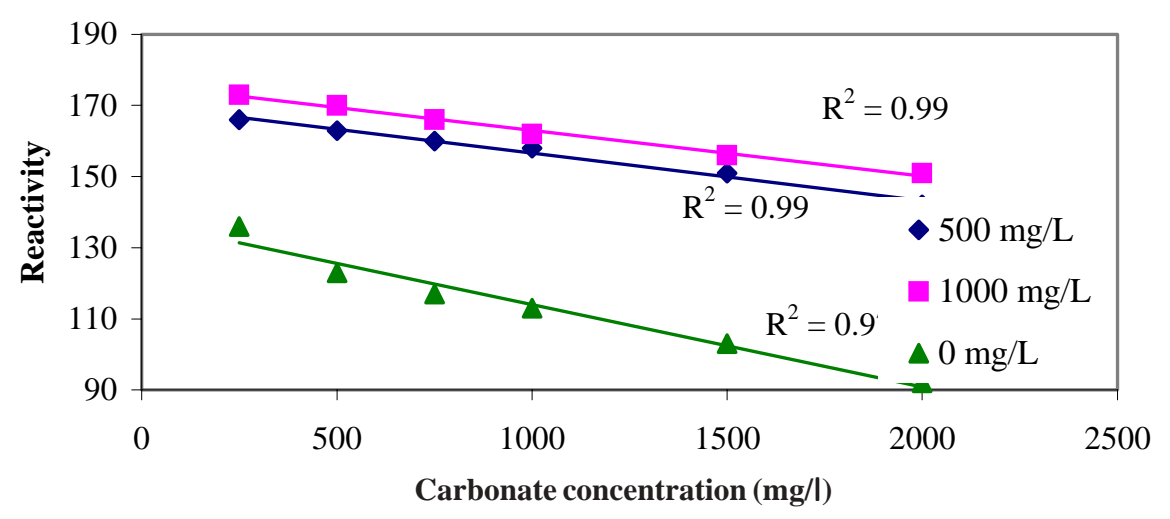

Figure 8

The effect of various chloride concentrations on lime slaking in carbonate ion-containing solutions

slaking rate to higher values than those obtained in the presence of the retarding ion alone. The higher concentration of chloride always caused the greater effect in this regard. In both cases the reactivities of the lime decreased linearly, with the effect of chloride being proportional to its concentration. In the case of the carbonate-containing solutions there was not as large a difference between the effect of the two chloride concentrations as there was in the case of the solutions containing sulphate. The hydration rates of all solutions containing carbonate and sulphate anions were, within experimental error, the same with $500 \mathrm{mg} / \mathrm{l}$ of chloride present. However, when at the higher concentration of 1000 $\mathrm{mg} / \mathrm{l}$ of chloride, the observed slaking rate is slightly higher (169 compared to 162) in the sulphate-containing solutions. Judging from the curves presented in Figs. 7 and 8, it seems that a sufficiently high concentration of chloride has a larger effect on the slaking rate of lime in solutions containing carbonate anions also, than in similar ones simultaneously containing sulphate anions. From a practical operational perspective this indicates that poor slaker performance can possibly be rectified by the addition of common salt to the hydrating mixture.

\section{Conclusions}

The following conclusions can be drawn from this work:

- $\mathrm{MgO}$, if present in small quantities $(<2$ to $3 \%)$ and if not hard burnt, can accelerate the hydration rate of unslaked lime. However, it has a very detrimental effect on the amount of grit formed during slaking and this can impair the operation of slakers in practical applications.

- The presence of chlorides alone in the slaking water linearly increases the hydration rate, while carbonate and sulphate anions decrease it linearly.

- Solutions containing sulphate anions produce more grit than those containing carbonate anions. This has practical implications for the operation of slakers under plant conditions.

- Carbonate anions have a greater effect in decreasing the slaking rate of lime than sulphate anions, both without and in the presence of chloride ions.

- This work for the first time describes quantitative relationships between various chemical influences and the slaking behaviour of the major source of unslaked South African lime.

\section{Acknowledgements}

The authors gratefully acknowledge the following institutions for financial support: NRF (National Research Foundation), Technikon Pretoria and the University of Pretoria. PPC (Pretoria Portland Cement) Lime Division kindly supplied the material used in this investigation.

\section{References}

ADDIS BJ (ed.) (1994) Fulton's Concrete Technology. Portland Cement Institute, Midrand, South Africa. Chapter 1.

CRC (1996) Handbook of Chemistry and Physics. CRC Press Inc., Boca Raton, Fl., USA. 66-67.

GHEEVARHESE O, STRYDOM CA, POTGIETER JH and POTGIETER SS (2002) The influence of chloride and sulphate ions on the slaking rate of lime derived from different limestone deposits in South Africa. Water SA 28 (1) 45-48.

NATIONAL LIME ASSOCIATION (1990) Lime handling, application and storage. Bulletin 213 ( $7^{\text {th }}$ edn.), Arlington, USA. 53-66.

OATES JAH (1998) Lime and Limestone Chemistry and Technology, Production and Uses. Weinheim: Wiley - VCH Publishers. 215.

POTGIETER JH, POTGIETER SS, MOJA SJ and MULABA-BAFUBIANDI A (2002a) An empirical study of factors influencing lime slaking. Part I: Production and storage conditions. Minerals Eng. 15 201-203.

POTGIETER JH, POTGIETER SS, MOJA SJ and MULABA-BAFUBIANDI A (2002b) The standard reactivity test as a measurement of lime's quality. J. of the SA Inst. of Mining and Metallurgy 102 (1) 67-69. 


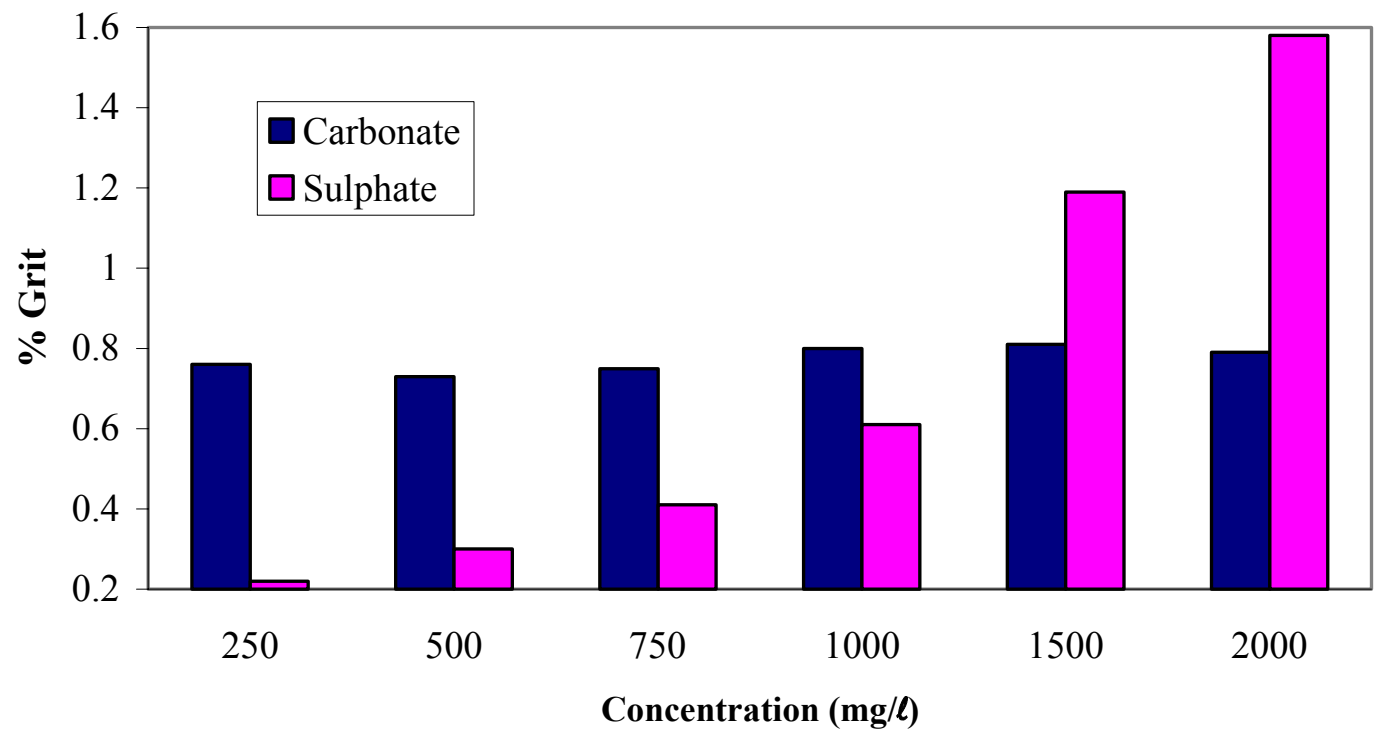

Figure 6 